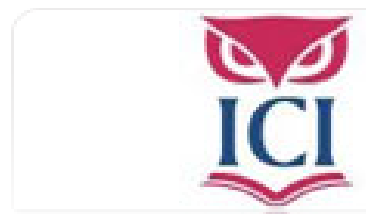

IUS. Revista del Instituto de Ciencias Jurídicas de Puebla A.C.

ISSN: $1870-2147$

revista.ius@hotmail.com

Instituto de Ciencias Jurídicas de Puebla A. C.

México

Pace, Alessandro

Los retos del constitucionalismo en el siglo XXI

IUS. Revista del Instituto de Ciencias Jurídicas de Puebla A.C., núm. 21, 2008, pp. 5-22

Instituto de Ciencias Jurídicas de Puebla A. C.

Puebla, México 


\section{LOS RETOS DEL CONSTITUCIONALISMO EN EL SIGLO XXI*}

Alessandro Pace ${ }^{* * *}$

SUMARIO

1. Algunos de los posibles escenarios del siglo XXI

2. Constitucionalismos y "constitucionalismo"

3. Constitucionalismo e interpretación por valores

4. Volver al constitucionalismo garantista

\section{RESUMEN}

El artículo explora algunos de los retos a los que se enfrenta el constitucionalismo moderno desde el punto de vista teórico, deteniéndose en particular en la apertura que ha habido de los límites en los contenidos y roles del constitucionalismo ante la impronta de regular nuevos contenidos y enfrentar nuevas problemáticas. Ello generalmente culmina admitiendo la noción de una Constitución descriptiva y aceptando otorgarle amplios poderes al poder político, consagrando los mecanismos de un Estado intervencionista que en muchos casos no tiene delimitado adecuadamente sus esferas de poder. Ante esto, el autor reivindica un regreso a la concepción de constitucionalismo como teoría jurídica de limitación y regulación del poder.

\section{ABSTRACT}

The article explores some from the challenges to those that faces the modern Constitutional Right from the theoretical point of view, analyzing in particular in the opening that there have been of the limits in the contents and functions of this discipline of the right in the face of the necessity of to regulate new contents and to face new problems. It generally culminates admitting the notion of a descriptive Constitution and accepting to grant wide powers to the political power, consecrating the mechanisms of a state interventionist. Before this, the author claims a return to the conception of Constitutional Right as artificial theory of limitation and regulation of the power.

\footnotetext{
* Conferencia impartida en las 11 Jornadas del Aula de Derecho Parlamentario (organizadas por la Universidad de Navarra y el Parlamento de Navarra) bajo el título "Veinticinco años de la Constitución española”, celebradas en Pamplona los días 13 y 14 de noviembre de 2003.

** Profesor ordinario de derecho constitucional en la Facultad de Derecho de la Universidad La Sapienza de Roma.
} 


\section{Algunos de los posibles escenarios del siglo XXI}

Un reconocido experto en cosmología y astrofísica, Martin Rees, refiriéndose al insólito y rápido aumento de la temperatura, ha sostenido que "hay sólo una posibilidad entre dos de que la raza humana llegue al siglo próximo." ${ }^{1}$ Los mismos temores ha expresado el paleontólogo Michael Benton, para quien "la temperatura de la tierra se encontraría escasamente a seis grados de alcanzar el nivel en el cual las formas de vida que conocemos -incluida la nuestra- no podrían sobrevivir"; y a propósito de esto la National Academy of Science de los Estados Unidos ha excluido definitivamente que el recalentamiento de la tierra se deba a causas naturales. ${ }^{2}$

La población de la tierra crece a un ritmo vertiginoso: de unos dos mil millones de habitantes en los años cincuenta, rondamos ahora los seis mil. Se estima que para el 2015 alcancemos los siete mil, y que en 2050, la cifra sea de entre 9000 y 10000 millones de habitantes. Ya hoy los recursos alimenticios e hídricos, sea como consecuencia de su distribución natural o por razones políticas y técnicas, son insuficientes, con la consiguiente elevadísima mortalidad (once millones de niños cada año). Se estima que en el 2025 dos mil millones de individuos no dispondrán de agua potable. ${ }^{3}$

El informe de la onU de este año a propósito de los desamparados y los que viven en situación de extrema pobreza dibuja un cuadro estremecedor: mil millones de personas (número que previsiblemente se multiplicará por dos para el 2030) sobreviven en condiciones infrahumanas: el 60\% en Asia, el 20\% en África y el 14\% en Sudamérica. La responsable de la agencia Habitat de la onu afirma a propósito que "uno de los problemas es que las mismas administraciones locales desconocen lo que ocurre al otro lado de los núcleos de chabolas -bidonville-, pues nadie se atreve a pasar la frontera".

A diario, la prensa informa de episodios de tortura, incluso en países que tenemos por altamente civilizados, sobre personas detenidas en el contexto de la lucha contra el terrorismo internacional. Es así significativo el caso de los prisioneros de la base americana de Guantánamo, que no son considerados por los Estados Unidos como prisioneros de guerra

${ }^{1}$ La afirmación está tomada de G. Sartori, "Homo stupidus, fermati in tempo", Corriere della sera, 17 de agosto de 2003, p. 1.

${ }^{2}$ Idem.

${ }^{3}$ G. Sartori y G. Mazzoleni, La terra scoppia. Sovrappopolazione e sviluppo, Rizzoli, Milano, 2003, passim.

${ }^{4}$ R. Romani, “Un miliardo di diseredati nelle baraccopoli”, Corriere della sera, 7 de octubre de 2003, p. 18. 
(que, como es sabido, se encuentran tutelados por la Convención de Ginebra), ni tampoco como ciudadanos comunes (también tutelados por las convenciones internacionales e incluso por las propias leyes federales americanas). Amnistía Internacional ha denunciado asimismo que se recurre sistemáticamente a la tortura en Cuba, Irán, Egipto, en los territorios ocupados por Israel, en Albania, Chechenia y en Sudáfrica. ${ }^{5}$

Por su parte, el Parlamento Europeo ha denunciado recientemente las brutalidades cometidas por funcionarios de policía en Europa sobre personas detenidas (con consecuencias mortales en diez casos), así como el deterioro de la situación de los detenidos en algunos países de la Unión Europea -entre ellos Italia- como consecuencia, principalmente, del hacinamiento carcelario. ${ }^{6}$

Igualmente el Parlamento Europeo ha condenado que no haya encontrado una respuesta legislativa en el seno de la Unión Europea el problema de la concentración de medios de comunicación en manos de algunos grandes grupos, y, en particular, que en Italia "se perpetúe una situación de concentración de los medios dependientes del presidente del Consiglio, sin que se haya adoptado una normativa con respecto al conflicto de intereses que se plantea".

Desde hace años, las pantallas de televisión se han convertido, en países que señalaríamos como altamente desarrollados, en lugar privilegiado y ansiado de la política, pues una importante parte del electorado (que en Italia se estima próxima al 20\%) depende de la televisión como única fuente de información. De ahí las preocupaciones que despierta en Italia el grupo mediático Berlusconi-Mediaset y, a nivel mundial, el grupo Murdoch, ambos operativos además de en el sector televisivo, en la prensa, en el mundo editorial, en la industria cinematográfica, etcétera. ${ }^{8}$

\footnotetext{
${ }^{5}$ El informe anual de Amnesty International para el año 2003 puede encontrarse en http://www.amnesty.it/pubblicazioni/rapporto2003/panoramica.php3

${ }^{6}$ Parlamento Europeo, Resolución de 4 de septiembre de 2003 sobre la situación de los derechos fundamentales en la Unión Europea (2002) (2002 / 2013 iNI).

${ }^{7}$ Parlamento europeo, Resolución de 4 de septiembre de 2003 sobre la situación de los derechos fundamentales en la Unión Europea, Op . cit. Ver también en la Comisión del Parlamento Europeo por la libertad y los derechos de los ciudadanos, la justicia y los asuntos internos, Informe sobre la situación de los derechos fundamentales en la Unión Europea de 17 de julio de 2003 (A5-0281/2003), tomada en consideración por la Resolución del Parlamento Europeo de 4 septiembre de 2003, arriba citada.

${ }^{8}$ La adquisición de las dos empresas que con anterioridad operaban en ltalia con retransmisiones televisivas de pago vía satélite (Telepiù y Stream) por parte de Sky ltalia del grupo Murdoch -y, en consecuencia de eso, la adquisición, por parte de tal grupo, de una posición de monopolio en las transmisiones televisivas codificadas vía satélite - podría, paradójicamente (pero... afortunadamente) constituir una vía para superar el duopolio televisivo formado por el medio público detenido por la RAl s.p.a. (con tres cadenas televisivas nacionales terrestres) y la empresa RTI s.p.a. (del grupo Berlusconi-Mediaset, con otras
} 
Desde hace unos años está en funcionamiento Echelon. Es éste un sistema de control vía satélite de la National Security Administration de los Estados Unidos -en el que participan también el Reino Unido, Canadá, Australia y Nueva Zelanda - con capacidad para interceptar el contenido de todas las comunicaciones telefónicas, telefax, telex y correo electrónico en todo el mundo: un sistema inicialmente limitado al espionaje militar (con base en un acuerdo adoptado en 1948), pero lo cierto es que actualmente -se dice- alcanza también al espionaje comercial.

Les ahorro la referencia a los gravísimos problemas institucionales y sociales relacionados con la llamada globalización de la economía, de la que supongo enterados a todos los presentes. ${ }^{9}$ Entro así en el tema de mi conferencia.

\section{Constitucionalismos y "constitucionalismo"}

Frente a los preocupantes escenarios a los que acabo de hacer referencia, me pregunto ahora si todos los gravísimos problemas puestos sobre la mesa, en la medida en que pueden ser afrontados mediante acuerdos internacionales y con medidas de orden legislativo, tienen que ver con el "constitucionalismo"; es decir, la cuestión es si la respuesta a los "retos" que dichos problemas plantean a los estados y a las organizaciones supranacionales deben formar parte de los objetivos de ese movimiento político, filosófico y cultural que comúnmente se designa con ese vocablo.

En otras palabras: ¿nuestra condición de constitucionalistas nos legitima para sentirnos en posesión de título para intervenir en cualquier problema de interés general que se suscite?

La duda se plantea porque, junto al significado clásico de "constitucionalismo", más restringido y garantista y centrado en la "teoría jurídica de los límites del poder político”, van abriéndose camino, también entre los juristas, concepciones omnicomprensivas de constitucionalismo, tales

tantas cadenas televisivas nacionales).

${ }^{9}$ Ver, sobre este punto, en la doctrina constitucional italiana, M. Luciani, "L'antisovrano e la crisi delle costituzioni”, en Rivista di diritto costituzionale, 1996, pp. 124ss, No. 165; G. Ferrara, "Costituzione e revisione costituzionale nell'età della mondializzazione", en Studi in onore di G. Guarino, Vol. 11, Cedam, Padova, 1998, pp. 218ss, 289ss; 1d., "La sovranità statale tra esercizio congiunto e delega permanente”, en AA.VV., Ripensare lo Stato, dirigido por S. Labriola, Giuffrè, Milano, 2003, pp. 685ss.; A. Baldassarre, Globalizzazione contro democrazia, Laterza, Bari-Roma, 2002, passim; 1d., "Globalizzazione e internazionalizzazione delle decisioni”, en AA.VV., Ripensare lo Stato, Op. cit., pp. 81ss. Algunas consideraciones sobre el tema se encuentran en G. Amato, Tornare al futuro. La sinistra e il mondo che ci aspetta, Laterza, Roma-Bari, 2002, pp. 57ss, 76, 86. 
como la "concepción de la Constitución"10 o aquella de "las tendencias constitucionales" ${ }^{11}$ y todavía otras más. ${ }^{12}$ Acepciones éstas que -salvo que se concrete su relación con la verdadera esencia del constitucionalismo, esto es, la "limitación legal del gobierno en contraposición al gobierno arbitrario"-13 despiertan cierta perplejidad en cuanto a su plena adecuación

${ }^{10}$ Sobre esta distinta acepción del vocablo constitucionalismo, ver G. Rebuffa, Costituzioni e costituzionalismi, Giappichelli, Torino, 1990, passsim, y M. Dogliani, Introduzione al diritto costituzionale, 11 Mulino, Bologna, 1994, pp. 199ss. Obviamente, tanto Rebuffa como Dogliani tienen bien presente también la acepción del constitucionalismo entendido como "teoría jurídica de los límites del poder político" (G. Rebuffa, Costituzioni..., Op. cit., pp. 113, 169ss.; M. Dogliani, Introduzione..., Op. cit., p. 35).

${ }^{11}$ En este sentido, ver, por ejemplo, G. Rolla, "La prospettiva dei diritti della persona alla luce delle recenti tendenze costituzionali”, en Studi in onore di L. Elia, t. 11, Giuffrè, Milano, 1999, pp. 1431ss.

${ }^{12}$ Ver, por ejemplo, Y. Higuchi, Le constitutionalisme, ponencia presentada en el xill Congreso lnternacional de Derecho Comparado, Montreal, 1990, p. 1 del texto mecanografiado, donde se habla de constitucionalismo como "supremacía de la Constitución”. Ver también P. Craig, "Constitutions, Constitutionalism and the European Union”, en European Law Journal, Vol. 7, 2001, p. 127, refiriéndose al constitucionalismo en el primero de los significados arriba indicados, subraya sin embargo la multiplicidad de los mismos. Análogamente ver G. de Burca y J. B. Aschenbrennen, "The Development of European Constitutionalism and the Role of the Eu Charter of Fundamental Rights", en Columbia Law Journal of European Law, Vol. 9, 2003, p. 360.

${ }^{13}$ En este sentido, ver en particular C. H. Mcillwain, Costituzionalismo antico e moderno (Constitutionalism Ancient and Modern, 1947), trad. it. Ver por Caprariis, Neri Pozza, Venezia, 1956, y C. Friedrich, Governo costituzionale e democrazia (Constitutional Government and Democracy, 1950), trad. it., M. Grego, Neri Pozza, Vicenza, 1963.

En la obra de B. Constant se subraya reiteradamente la oposición del constitucionalismo al gobierno arbitrario. Ver B. Constant, Principes de polititique (1815), Cap. xvı1; ld., Réflexions sur les Constitutions et les Garanties, avec une Esquisse de Constitution (1814-1818), Anexo вв; ld., De la Responsabilité des Ministres (1814-1818), Caps. v y xiv; 1d., Des Réactions politiques (1797), Cap. 1x; 1d., De l'Esprit de Conquete, Cap. xı. Todas estas obras se reúnen en B. Constant, Cours de politique constitutionnelle, a cargo de E. Laboulaye, Guillaumin, Paris, 1872, t. 1, pp. 146ss, 374s, 403, 433ss.; t. 11, pp. 116ss., 222ss (ahora reproducidas en edición facsímil por la editorial Slatkine, Genéve-Paris, 1982).

A la acepción axiológica de constitucionalismo se refiere G. de Ruggiero, Storia del liberalismo europeo (1925), Laterza, Bari, 1959, 167ss, recordando el liberalismo francés de la Francia de la Restauración y, en particular, a Benjamin Constant. Ver también, en el mismo sentido, las numerosas e importantes contribuciones de N. Matteucci, "Positivismo giuridico e costituzionalismo", en Rivista trimestrale di diritto e procedura civile, 1963, pp. 1039ss, 1059; 1d., Organizzazione del potere e libertà. Storia del costituzionalismo moderno, Utet, Torino, 1976; 1d., Lo Stato moderno. Lessico e percorsi, 11 Mulino, Bologna, 1993, pp. 127ss, 155 (y también, las referencias al papel, en ese sentido, desempeñado por B. Constant); 1d. voz "Costituzionalismo", en Dizionario della politica, dirigido por N. Bobbio y N. Matteucci, Utet, Torino, 1976, 263ss; 1d., voz "Costituzionalismo", en Enciclopedia delle scienze sociali, Vol. 11, Istituto dell'Enciclopedia italiana, Roma, 1992, pp. 521-523, 534ss, y también la indicación de que el constitucionalismo "no es, hoy, un término neutro para un uso meramente descriptivo, dado que su significado engloba el valor que a la vez esta implícito en la palabra "constitución” y "constitucional" (un conjunto de concepciones políticas y de valores morales), intentando distinguir las que fueron soluciones contingentes (...) de aquellas cuyos caracteres son permanentes".

En el mismo sentido ver también C. M. G. Himsworth, "Constitutionalism”, en AA.VV., United Kingdom Law in the 1990s, dirigido por J. P. Gardner, U. K. National Committee of Comparative Law, London, 1990, pp. 282ss; M. R. Damaska, Reflections on American Constitutionalism, en AA.VV., U. S. Law in an Era of Democratization, dirigido por J. N. Hazard y W. J. Wagner, suplemento de The American Journal of Comparative Law, Vol. xxxvill, 1990, pp. 421ss; M. Aragón Reyes, Constitución y control del poder, Ediciones Ciudad Argentina, Buenos Aires, 1995, pp. 15ss, aborda la evolución histórica del constitucionalismo garantista; G. Rebuffa, Costituzioni e costituzionalismi, Op. cit., passim, en especial 
a los fines históricos del constitucionalismo, que "siempre ha aspirado a poner el límite de la ley a quien tiene de hecho el monopolio de la fuerza, erigiendo así en soberanas a las leyes y no a los hombres". ${ }^{14}$

Dos son los apuntes críticos que pueden hacerse a estas nociones de constitucionalismo que no subrayan que poner límites a la arbitrariedad de los gobernantes es esencialmente el fin a que debe mirar el constitucionalismo.

Primer apunte crítico. Si nos limitamos a afırmar que el "constitucionalismo" designa genéricamente la supremacía de la constitución, o bien una concepción de la constitución, o una mera tendencia constitucional, se termina, incomprensiblemente, por hacer entrar en el concepto de "constitucionalismo” también concepciones y tendencias constitucionales que, aunque con las mejores intenciones, prefiguran sistemas de gobierno en los cuales se acaba atribuyendo al Ejecutivo, aunque democráticamente elegido, amplísimos poderes discrecionales, y se reducen a la mínima expresión los controles sobre el mismo. ${ }^{15}$

No es por eso casual que uno de los más destacados estudiosos del "constitucionalismo" como sistema de limitación del poder, Charles McIllwain, refiriéndose a la política del New Deal propugnada por F. D. Roosevelt, hubiera expresado, ya en 1937, sus temores a "la antigua alianza entre

pp. 169ss., quien subraya que, en las distintas formulaciones del constitucionalismo (entendido como concepción de la Constitución) por él examinadas (Montesquieu, Locke, Sieyes, Paine, Tocqueville), está siempre presente un elemento común: "la idea de que la actividad de los sujetos públicos deba ser sometida al derecho"; M. Fioravanti, Costituzione, 11 Mulino, Bologna, 1999, pp. 85, 130, 151ss, 160ss., que subraya en varias ocasiones la coesencialidad al constitucionalismo moderno de las ideas de límite, equilibrio, garantía y moderación; S. Gordon, Controlling the State: Constitutionalism from Ancient Athens to Today, Harvard Univ. Press, Cambridge, Mass., 1999, passim, en especial pp. 236s, que afirma: "Constitutionalism, as 1 have been using that term, refers to a political system that imposes constraints upon the exercise of political power".

La obligada conexión del constitucionalismo, entendido como tendencia constitucional, con la tutela de los derechos de la persona, es subrayada también por G. Rolla, "1 diritti fondamentali nel costituzionalismo contemporaneo", en AA.WV., Tecniche di garanzia dei diritti fondamentali, Op. cit., pp. 4ss. Es sorprendente, pero no existe en la doctrina alemana, que yo sepa, un concepto teórico de "constitucionalismo" equivalente al aquí expuesto. En efecto, con el término Konstitutionalismus se alude por los estudiosos alemanes, a la teoría de los límites del poder monárquico, y por consiguiente, a un concepto situado históricamente (en este sentido ver P. Badura, Staatsrecht2, Beck, München, 1996, pp. 24s y 79s), allí donde los valores del constitucionalismo son propios de la noción de Verfassungsstaatlichkeit (P. Badura, Staatsrecht2, pp. 11s, en especial p. 14; H. Denninger, Staatsrecht, Vol. ı, Rohwolt, Hamburg, 1979, pp. 23ss; G. F. Schuppert y C. Bumke, Die Konstitutionalisierung der Rechtsordung, Nomos Verlag, Baden-Baden, 2000).

${ }^{14}$ N. Matteucci, Positivismo giuridico e costituzionalismo, Op. cit., p. 1041.

${ }^{15}$ Precisamente P. Biiscartte di Ruffia, voz "Costituzionalismo", en la Enciclopedia del diritto, Vol. xl, Giuffrè, Milano, 1962, p. 130, subrayaba que, habiendo desaparecido las distintas formas de Estado autoritario, las formas de gobierno marxista, entonces vigentes, se encontraban "en manifiesto antagonismo con las formas propias de los restantes estados de democracia clásica”. 
el reformador social y el liberal constitucionalista”. Observaba McIllwain lo siguiente: "En el pasado, luchar contra los abusos implicaba la defensa de los derechos individuales contra un poder despótico. Extrañamente, hoy, reformar los abusos se traduce para la mayor parte de los reformadores en un aumento de los poderes de gobierno." ${ }^{16}$ Estudios posteriores han subrayado también con preocupación cómo el nuevo fenómeno que ha caracterizado el Estado "activo" (o "intervencionista") es "la indeterminación de las intervenciones en este campo, y la ausencia en ellas con carácter general de barreras y límites predeterminados". ${ }^{17}$

Tampoco cabe pensar - de acuerdo con los principios del constitucionalismo clásico- que la investidura democrática elimine de raíz tales problemas. En efecto, en un sistema regido por una Constitución escrita y liberaldemocrática, no sólo el Gobierno ejerce "funciones" (esto es, poderes atribuidos con una finalidad prevista y fijada por ley, y de acuerdo con los principios de legalidad y tipicidad de los actos administrativos); no sólo los otros poderes deben actuar de conformidad con el principio de "competencia", sino que hasta el mismo "pueblo soberano" -como subraya el Art. 1.2 de la Constitución italiana- ejerce la soberanía "en la forma y con los límites de la Constitución". Por consiguiente, la investidura democrática no pone al elegido por encima de la Constitución.

En otras palabras, y simplificando al máximo, no existe un "constitucionalismo" de Rousseau, y menos, un "constitucionalismo" jacobino; sí existe por el contrario el "constitucionalismo" de Montesquieu, de Locke, de Hamilton, de Constant y de Tocqueville. Rousseau, por sí mismo, conduce al radicalismo democrático $\mathrm{y}$, por consiguiente, a la dictadura. ${ }^{18}$

Segundo apunte crítico a las nociones de constitucionalismo que no subrayan la necesidad de poner límites a la arbitrariedad de los gobernantes. No es exacto que el "constitucionalismo" esté en posesión de técnicas para resolver cualquier problema, nacional o internacional, por el hecho

\footnotetext{
${ }^{16} \mathrm{La}$ afirmaciones referidas de $\mathrm{C}$. H. Mcillwain han sido recogidas y favorablemente comentadas por $\mathrm{N}$. Matteucci, voz "Costituzionalismo", en Enciclopedia delle scienze sociali, Vol. 11, 1stituto dell'Enciclopedia italiana, Roma, 1992, p. 535.

${ }^{17}$ G. Rebuffa, Costituzioni e costituzionalismi, Op. cit., p. 147.

${ }^{18}$ Sobre la concepción de la Constitución de J-. J. Rousseau y sobre la visión posterior de M. Robespierre, ver G. Rebuffa, Costituzioni e costituzionalismi, Op. cit., pp. 80ss. Fuertemente crítico con el pensamiento de Rousseau ver, entre otros, B. Constant, Principes de politique applicables à tous les gouvernments (18061810), dirigido por E. Hofman, Hachette, Paris, 1997, pp. 29ss y 84ss. También en este sentido, como es sabido, H. Arendt, Sulla rivoluzione (On Revolution, 1966), trad. it. M. Magrini, Comunità, Milano, 1996, pp. 93ss. En el sentido del texto ver también A. Barbera, "Le basi filosofiche del costituzionalismo", en AA.V., Le basi filosofiche del costituzionalismo, dirigido por A. Barbera, Laterza, Bari, 1997, p. 18.
} 
de tener una relevancia política. Por una parte, una afirmación de estas características acaba confiriendo al concepto de "constitucionalismo" un alcance puramente descriptivo (en el sentido de entender que en el constitucionalismo cabe todo), y por otra, termina por construir, demasiado sencillamente, una relación sucesiva entre Constitución (como producto del constitucionalismo) y la actividad legislativa que vendría a ser desarrollo de la primera. ${ }^{19}$ Es decir, como si en la Constitución el legislador ordinario encontrara el exhaustivo fundamento, y no tanto el límite (algunas veces positivo, pero en general negativo) de sus decisiones políticas.

Pues bien, me parece que, mientras el concepto de Constitución sea puramente descriptivo (en el sentido de que las constituciones podrían también no tutelar los derechos fundamentales, no contemplar la división de poderes, no ser democráticas, etc.), no puede decirse lo mismo del constitucionalismo.

En favor del concepto descriptivo de Constitución me limito a observar que, siguiendo la tesis contraria -la de la naturaleza esencialmente axiológica del concepto de Constitución (defendida por autorizadísimos estudiosos de la disciplina, tanto españoles como italianos) ${ }^{20}-$, se termina por negar, contra la misma evidencia histórica, el nombre de Constitución a documentos solemnes que, por no ajustarse al modelo ideológico

\footnotetext{
${ }^{19}$ Esta tesis, aquí no compartida, es seguida, en Italia, explícitamente por F. Modugnp, L'invalidità della legge, Vol. 1, Giuffrè, Milano, 1970, pp. 148ss, 160; 1d., L'invalidità della legge, Vol. 11, Giuffrè, Milano, 1970, pp. 3ss; ld., voz "Legge (vizi della)", en Enciclopedia del diritto, Vol. xxil1, Giuffrè, Milano, 1973, p. 1036. En sentido contrario se manifiesta la mayoría de la doctrina italiana (ver por todos L. Paladin, Le fonti del diritto, 11 Mulino, Bologna, 1996, pp. 139 y 174s). En este último sentido, en la literatura extranjera, ver por ejemplo, W. G. Andrews, Constitutions and Constitutionalism, Princeton, New Jersey, 1968, pp. 21s, cit. por W. H. McConnel, Canadian Constitutionalism, ponencia presentada en el xul Congreso Internacional de Derecho Comparado, Montreal, 1990, p. 3 del texto mecanografiado: "Many of the norms of constitutionalism remained outside the documentary framework..."

${ }^{20}$ Entre los muchos defensores de esta tesis, ver F. Rubio Llorente, "La Constitución como fuente del derecho" (1979), en ld., La forma del poder, Centro de Estudios Constitucionales, Madrid, 1993, p. 87; 1d., voz "Constitución (derecho constitucional)”, en Enciclopedia jurídica básica, Vol. 1, Civitas, Madrid, 1995, p. 1525; M. Aragón Reyes, Sobre las nociones de supremacía y supralegalidad constitucional, Universidad Externado de Colombia, Bogotá, 1986, p. 17; G. Ferrara, Costituzione e revisione costituzionale, Op. cit., p. 245; A. Spadaro, Contributo per una teoria della costituzione, Vol. 1, Giuffrè, Milano, 1994, pp. 72s; M. Luciani, L'antisovrano e la crisi delle costituzioni, Op. cit., p. 154.

No discuto - porque me parece exacta- la afirmación de M. García Pelayo, Derecho constitucional comparado, Alianza Editorial, Madrid, 1984, pp. 34ss, en especial p. 55, según el cual de los tres conceptos de Constitución por él ilustrados (el racional-normativo, el histórico y el sociológico), sólo el primero -esto es, aquel que se inspira en el Art. 16 de la Declaración de los Derechos del Hombre- ha sido importante para la ciencia del derecho constitucional (preciso, ha sido importante para aquel movimiento cultural que se llama constitucionalismo). Pero decir esto no significa negar que pudo haber constituciones meramente organizativas o que no tutelaran los derechos del hombre de acuerdo con la ideología liberal.
} 
del Art. 16 de la Declaración francesa de los Derechos del Hombre y del Ciudadano de 1789, han sido, sin embargo, formalmente denominados "constituciones", y así han operado como leyes superiores en los respectivos ordenamientos. ${ }^{21}$ En otras palabras, no puedo negar la naturaleza de Constitución a las constituciones napoleónicas y a las constituciones de los países del socialismo real, por el hecho de que no hayan sido "garantistas" en el sentido propio de los regímenes liberaldemocráticos (se dice, en efecto, que éstas serían constituciones nominales o pseudo-constituciones o constituciones fachada). ${ }^{22}$ Como decía, no puede dudarse que tales constituciones fueron "efectivas" -y lo fueron de hecho-, y esto no sólo porque su vigencia estaba asegurada por la fuerza, sino también porque millones de personas, para bien o para mal, las han tenido por tales y así lo han creído.

Sin embargo, no me parece que tenga sentido negar la naturaleza axiológica y prescriptiva del concepto de constitucionalismo (y, consiguientemente, tampoco me parece que tenga sentido negar la naturaleza prescriptiva y axiológica al concepto de "Estado constitucional", es decir, aquel que se desenvuelve de conformidad, entre otros, con los principios del constitucionalismo garantista). Ciertamente, afirmándose la naturaleza descriptiva del concepto, se terminaría por negar cualquier identidad a aquel movimiento político, filosófico y cultural.

En conclusión, o el constitucionalismo se ajusta al modelo del citado Art. 16 de la Declaración de 1789 y sus técnicas están orientadas a limitar, ya sea funcional o estructuralmente, el poder político, o no es constitucionalismo. $^{23}$

\footnotetext{
${ }^{21}$ Ver en tal sentido G. Jellinek, La dottrina generale dello Stato (Allgemeine Staatslehre, libro 11, 1914), trad. it. M. Petrozziello, Giuffrè, Milano, 1949, p. 108, no así N. Bobbio, Lettera a Nicola Matteucci del 25 luglio 1963, publicada al pie del ensayo de C. Margiotta, "Bobbio e Matteucci su costituzionalismo e positivismo giuridico con una lettera di Norberto Bobbio a Nicola Matteucci”, en Materiali per una storia della cultura giuridica, 2000, 387ss y pp. 422ss, sale al paso de la crítica de Bobbio a Matteucci. Obsérvese que mientras Matteucci confunde el concepto de constitución con el concepto axiológico de constitucionalismo, Bobbio confunde, a su vez, el concepto de constitucionalismo con el concepto descriptivo de constitución.

Sobre el problema del significado de constitución, ver también por posteriores indicaciones, G. Sartori, Elementi di teoria politica, 11 Mulino, Bologna, 1987, 11ss, 21ss. Sobre la contraposición constituciónconstitucionalismo, ver A. Barbera, Le basi filosofiche del costituzionalismo, Op. cit., pp. 3s; A. Pace, Potere costituente, rigidità costituzionale, autovincoli legislativi, Cedam, Padova, 2002, p. 112.

${ }^{22}$ G. Sartori, Elementi di politica..., Op. cit., pp. 22ss.

${ }^{23}$ R. M. van Male, "Constitutionalism in the Netherlands", in AA.VV., Netherlands Reports to the Thirteenth International Congress of Comparative Law (Montreal, 1990), тмс Asser Instituut, The Hague, 1990, p. 349: "The broad and perhaps somewhat vague concept of constitutionalism presents one essential feature: limitation on government by law...”
} 


\section{Constitucionalismo E INTERPRetación POR VAlores}

Aún es preciso hacer aquí una puntualización: la distinción entre lo que es y lo que no es constitucionalismo, no sólo es válida a los efectos de distinguir los "estados constitucionales" 24 de los "no constitucionales". Pues vale también en el interior de un ordenamiento constitucional liberaldemocrático para valorar la conformidad con la lógica del constitucionalismo, de las técnicas jurídicas utilizadas por el legislador, por la jurisprudencia y por la doctrina en relación con la limitación y disciplina del poder (público y privado) y los derechos individuales.

Consiéntaseme a propósito de esto una breve digresión. En una conferencia que pronuncié, hace unos años, en el seno de un congreso italo-español, ${ }^{25}$ tuve ocasión de plantear la tesis según la cual, en un ordenamiento liberaldemocrático, solamente una interpretación constitucional que sea respetuosa con los enunciados de la Constitución, si bien sensible a la evolución histórica, puede decirse conforme a los principios del "constitucionalismo".

A mi juicio, se puede sostener que, si se parte de la noción garantista de "constitucionalismo"26, la coherencia impone que sólo una interpretación que tome "en serio" el texto y la estructura de la Constitución ${ }^{27}$-para la

${ }^{24}$ Sobre el concepto axiológico de Estado constitucional, ver en particular, P. Badura, Staatsrecht 2, $O p$. cit., pp. 11s, 78s, 267ss; P. Häberle, voz "Potere costituente (teoria generale)", en Enciclopedia giuridica, Vol. xxil (actualización del 2000), lstituto dell'Enciclopedia italiana., Roma, 1990ss, p. 14ss; 1d., voz Stato costituzionale, v) Prospettive future, también, Vol. xxx (actualización del 2000), 1stituto dell'Enciclopedia italiana, Roma, 1993ss, pp. 1ss.

${ }^{25}$ A. Pace, "Costituzionalismo e metodi interpretativi dei diritti fondamentali", ponencia presentada en el Congreso italo-español sobre Le nuove frontiere dei diritti fondamentali celebrado en la Certosa di Pontignano (Siena) en abril de 2000. La conferencia está publicada en AA.VV., Tecniche di garanzia dei diritti fondamentali, dirigida por G. Rolla, Giappichelli, Torino, 2001, pp. 27ss. Más extensa y en más profundidad ha sido también publicada en la revista Quaderni costituzionali, 2001, pp. 35ss, con el título "Metodi interpretativi e costituzionalismo".

${ }^{26}$ C. H. Mcillwain, Costituzionalismo antico e moderno, Op. cit., p. 30.

${ }^{27}$ L. H. Tribe, "Taking Text and Structure Seriously: Reflections on Free-form Method in Constitutional Interpretations", en Harvard Law Review, Vol. 108 (1995), pp. 1221ss, crítica a B. Ackerman y D. Golove, "Is NAFTA Inconstitutional?", Ibidem, Vol. 108 (1995), pp. 799ss, los cuales sostienen que apelando a ciertos presupuestos, el legislador federal podría establemente aprobar leyes expresamente derogatorias de la Constitución sin seguir el procedimiento previsto en el Art. $v$ de la Const. USA. En favor de tal interpretación free-form, ver también B. Ackerman, We the People. 2. Transformations, Harvard Univ. Press, Cambridge, Mass., 1998, a propósito de esto ver T. Groppi, "We the People: Transformations. Considerazioni su un libro di Bruce Ackerman”, en Politica del diritto, 1999, pp. 187ss. Sobre el problema de la interpretación constitucional ver también, más reciente, L. H. Tribe, American Constitutional Law, 3, Foundation Press, New York, 2000, pp. 31ss, y asimismo acerca de los criterios sobre la interpretación textual: 1) la atención a la estructura constitucional; 2) el criterio histórico; 3) la conformidad con l'etos nacional; 4) la importancia de los precedentes jurisprudenciales; 5) la combinación ecléctica de los criterios indicados, en el conocimiento de la ausencia de un criterio cierto y del resultado interpretativo 
cual los enunciados constitucionales constituyen el límite insuperable de las posibilidades "creativas" del intérprete ${ }^{28}-\ldots$ sólo una interpretación así, alejada de otros métodos interpretativos (tales como, por ejemplo, la llamada "interpretación por valores"), es efectivamente funcional, si lo que se pretende es limitar el poder y obstaculizar los excesos de la interpretación jurídica.

Por el contrario, el planteamiento interpretativo de las distintas teorías de los valores ${ }^{29}$ es "normativo-sustancial" y, por tanto, free-form: $:^{30}$ esto es, pretende solamente la "racionalidad" con respecto al "valor" que subyace en el enunciado constitucional, ${ }^{31}$ pero no la conformidad del resultado interpretativo con el enunciado en sí mismo considerado. ${ }^{32} \mathrm{Y}$ es ahí precisamente donde anida el riesgo de las soluciones arbitrarias, del subjetivismo de muchas "ponderaciones" entre valores y del abuso del criterio de razonabilidad (también, y sobre todo, para "salvar" las leyes de una declaración de inconstitucionalidad).

Soy consciente de que esta tesis podrá no ser compartida y que, de todos modos, no es generalmente aceptada, porque presupone la existencia

también cierto (Ibidem, p. 88).

${ }^{28}$ K. Hesse, Grundzüge des Verfassungsrechts der BRD, 19, Müller, Heidelberg, 1993, p. 14 (n. 33); 1d., "El texto constitucional como límite de la interpretación", en AA.V., División de poderes e interpretación, bajo la dirección de A. López Pina, Civitas, Madrid, 1987, p. 184; A. Pace, Metodi interpretativi e costituzionalismo, Op. cit., p. 45.

${ }^{29}$ Véase una reseña en M. Aragón Reyes, Constitución y control del poder, Op. cit., pp. 42ss, que subraya justamente la identidad de fondo de teorías como la "Constitución como norma abierta" y la "Constitución como sistema material de valores", estando ambas teleológicamente orientadas. Pero las reservas, con respecto a ellas, no nacen aquí, puesto que todas las disposiciones presuponen siempre un juicio de valor. El problema surge cuando los intérpretes, en nombre de los valores en ellas soterrados, pretenden ir contra los propios enunciados constitucionales. Lo cual no es jurídicamente admisible cuando se hace con constituciones escritas y articuladas como lo son la italiana y la española (en este sentido, y a propósito de esta última, ver L. López Guerra, en L. López Guerra, E. Espón, J. García Morillo, P. Pérez Tremps, M. Satrústegui, Derecho constitucional 2, Tirant lo Banch, Valencia, 1994, pp. 33s); P. Badura, Staatsrecht, Op. cit., p. 16).

${ }^{30}$ Sobre este punto ver también C. Wolfe, The Rise of Modern Judicial Review. From Constitutional Interpretation to Judge-Made Law, Rohman \& Littlefield, Lanham, Ma., 1994. Sobre la difundida tendencia a superar el texto normativo, también y sobre todo en materia de derechos fundamentales, y sobre las posibles causas de tal fenómeno, ver F. Pizzetti, "L'ordinamento costituzionale per valori", en Diritto ecclesiastico, 1995, p. 91ss.

${ }^{31}$ Ver, en el sentido criticado, A. Baldassarre, "Costituzione e teoria dei valori", en Politica del diritto, 1991, p. 654; 1d., Il problema del metodo nel diritto costituzionale, ponencia presentada al seminario organizado por la Asociación Italiana de Constitucionalistas, celebrado en Messina el 23 de febrero de 1996, recogido también en AA.V., Il metodo nella scienza del diritto costituzionale, Cedam, Padova, 1997, p. 100.

${ }^{32}$ Es sintomático que la teoría costruzionista (en su defensa ver B. Axkerman, We the People, 1. Foundations, Harvard Univ. Press, Cambridge, Mass., 1993, pp. 6ss) se haya incluido entre los métodos interpretativos contra constitutionem por V. García Tomás, "Valores, fines y principios constitucionales", en Revista Peruana de Derecho Constitucional, No. 1, 1999, pp. 635s. 
de una forma de Estado liberaldemocrática y de una Constitución, además de escrita, con un texto articulado (como es el caso precisamente de las constituciones italiana y española). Lo que pretendo subrayar con este ejemplo es que el concepto de constitucionalismo es, por un lado, más restringido que aquel de "concepción de la constitución" y el de la "tendencia constitucional” y, por otro, puede tener consecuencias más radicales.

En otras palabras, no es suficiente afirmar que el constitucionalismo se articula en torno a cinco pilares (la Constitución escrita, el poder constituyente, la declaración de derechos, la separación de poderes y el control jurisdiccional de constitucionalidad) $3^{33}$ es preciso añadir también que el constitucionalismo implica un planteamiento metodológico siempre dirigido a reforzar el límite del poder para evitar las arbitrariedades, cualquiera que sea el problema en liza: el contenido de los derechos constitucionales o los poderes del Ejecutivo, la inmunidad del jefe del Estado o de los miembros del Parlamento, las funciones del Tribunal Constitucional, u otros de igual calado. Obviamente, no puede perderse de vista la eficiencia de los poderes públicos, pero, insisto, evitando siempre que la necesaria discrecionalidad (que siempre está limitada, al menos desde una perspectiva finalista) no redunde nunca en arbitrariedad.

Podría objetarse que una tesis de este género identifica exclusivamente el constitucionalismo con aquello que ha teorizado y "producido" los derechos de primera generación (o sea, los derechos "de oposición" o las libertades todavía llamadas hoy inexactamente "negativas"), ${ }^{34}$ y sin embargo, termina por pasar por alto el constitucionalismo que ha teorizado y "producido" los derechos de segunda generación (los derechos sociales: es decir, los derechos a la educación, a la asistencia sanitaria, a la seguridad social y a la asistencia jurídica gratuita), así como al que ha teorizado y "producido", en sede internacional, los llamados derechos de tercera generación (derechos a la paz, al desarrollo, al medio ambiente y al patrimonio de la humanidad). ${ }^{35}$

${ }^{33}$ En este sentido ver N. Matteucci, voz "Costituzionalismo", en Enciclopedia delle scienze sociali, $O p$. cit., p. 522.

${ }^{34}$ En contra de esta inexacta identificación que aún perdura ver últimamente A. Pace, Problematica delle libertà costituzionali. Parte generale 3, Cedam, Padova, 2003, pp. 74s.

${ }^{35} \mathrm{~A}$. Amor, Les droits de l'homme de la 3.e génération, ponencia general presentada al 11 Congreso Mundial de la Asociación Internacional de Derecho Constitucional, Paris-Aix en Provence, 31 de agosto-5 de septiembre de 1987. G. Ferrera, "Rappresentanza e governo nazionale" (1988), en 1d., L'altra riforma, nella Costituzione, Manifestolibri, Roma, 2002, p. 28, se refiere, significativamente, al problema de la representación de las futuras generaciones, y, esto es, "a la cuestión de la conservación de la especie y a la garantía de la diginidad de su desarrollo". 
Una objeción de este tipo sería seguramente inexacta. Mientras los derechos sociales, en la medida en que se dirigen a emancipar a las personas de la necesidad, son "precondición" para el pleno ejercicio de la libertad individual $^{36}$-allí donde, por otra parte, la libertad política y los derechos de participación política constituyen, como ya intuyó Benjamin Constant, las garantías (aunque no las únicas) de tal libertad-, ${ }^{37}$ los llamados derechos de la tercera generación, son, bien mirados derechos "de oposición".

Con estos últimos, se explica, más o menos, por una parte, a nivel internacional, el intento de limitar el poder de los estados para poner en marcha actuaciones bélicas, salvo en el caso de legitima defensa, y de impedir que los estados mismos descuiden los problemas del medio ambiente y del ecosistema; y se explica, por otra parte, a nivel nacional, el intento de conferir ya sea a los poderes públicos o a los privados la posibilidad de controlar la producción y el comercio ilegítimo de armas, de contener la destrucción del patrimonio ambiental, o, en fin, de limitar la contaminación electrónica, acústica y atmosférica.

La perplejidad que suscitan los derechos fundamentales de la tercera generación no concierne a su naturaleza de derechos "de oposición", sino a la difícil identificación en las proclamaciones internacionales que contemplan esos derechos con situaciones jurídicas subjetivas accionables. ${ }^{38}$

Por último, una rápida pero también importante advertencia. Ya he manifestado mi desconfianza acerca de la teoría de la interpretación por valores. Por eso me parece significativo subrayar lo que ha puesto de relieve uno de los más agudos -y al propio tiempo razonables- defensores de la importancia determinante de los valores. Y es que, "incluso antes que la preeminencia de un planteamiento de tipo sistémico", la "incorporación" de la garantía de los derechos en la "constelación de los valores

\footnotetext{
${ }^{36}$ Ver las bellísimas páginas de C. Rosselli, Socialismo liberale (1930), Einaudi, Torino, 1979, pp. 89ss.

${ }^{37}$ B. Constant, De la liberté des anciens comparée à celle des modernes (1819), en ld., Cours de politique constitutionnelle, Op. cit., t. 11, p. 555.

${ }^{38}$ Piénsese en el Art. 11 C. It. a propósito del repudio de la guerra, del cual no cabe deducir un "derecho a la paz" como derecho autónomo alegable ante los tribunales. Lo admite el mismo L. Chieffi, Il valore costituzionale della pace, Liguori, Napoli, 1990, 193s. Eso no es poco, el rechazo a la guerra puede constituir, en efecto, la ocasión para el ejercicio de otros derechos constitucionales autónomamente exigibles, como la libertad de manifestación y de propaganda, la libertad de conciencia (deducible no del Art. 2 C. 1t., pero sí de todas las disposiciones constitucionales que tutelan el ejercicio de los comportamientos materiales que reflejan al pensamiento y las convicciones internas: Arts. 19, 21, 23, 33 etc.), la libre competencia (que se encuentra en el Art. 41.1 C. It.: tal libertad podría verse deslealmente alegada por quienes exportasen material bélico sin la necesaria autorización), o cosas de esta naturaleza. Sobre este punto ver también P. Barile, "Nuovi diritti e libertà fondamentali”, en AA.VV., Nuovi diritti dell'età tecnologica, dirigido por F. Riccobono, Giuffrè, Milano, 1991, p. 7.
} 
constitucionales" no comporta un "peligro de homologación, o mejor de una renuncia al significado 'de oposición' de los derechos de libertad" ${ }^{39}$ Una duda, esta última -lo digo a modo de inciso- que, sin embargo, puede surgir si se admite que la "Constitución como conjunto de valores" puede, aunque sea subrepticiamente, prevalecer sobre la Constitución escrita. Por todo lo dicho, esta solución no me parece conceptualmente posible, al menos, en lo que se refiere a constituciones detalladamente articuladas como es el caso de la española ${ }^{40}$ y de la italiana, en las cuales para la resolución de antinomias no se puede pasar por alto el respeto a los enunciados textuales.

\section{Volver al constitucionalismo garantista}

Me he detenido en subrayar cuáles son las notas esenciales de la noción de constitucionalismo, porque sostengo que el verdadero reto que hoy tiene ante sí, es encontrar y reafirmar su propia identidad originaria como teoría jurídica de los límites al poder político. Eso significa que todos nosotros -teóricos de esta disciplina u operadores prácticos- debemos reflexionar acerca de sus contenidos en nuestra labor ordinaria, a fin de verificar si estamos siendo, y en qué medida, fieles a esta filosofía política y, en consecuencia, reflexionar sobre cuál ha sido y cuál debe ser nuestro papel en la sociedad, ${ }^{41}$ sin presentar como constitucionalismo cualquier teorización constitucionalista.

Por el contrario. No me parece que tenga mucho sentido el otro planteamiento con que podría abordarse el tema de mi conferencia, consistente en verificar detalladamente si el constitucionalismo -en uno de los diferentes significados que circulan- puede desempeñar alguna función sobre

39 P. Ridola, Diritti di libertà e costituzionalismo, Giappichelli, Torino, 1997, pp. 4ss, 6, 33ss, con referencia explícita a la conocida conceptuología de N. Luhmann, Sistemi sociali. Fondamenti di una teoria generale, trad. it., 11 Mulino, Bologna, 1990, pp. 671ss.

${ }^{40} \mathrm{Si}$ bien es verdad que el artículo 1.1. de la Constitución española proclama que "España se constituye en un Estado social y democrático de derecho que propugna como valores superiores de su ordenamiento jurídico la libertad, la justicia, la igualdad y el pluralismo político", eso no significa que en la aplicación jurisdiccional de los valores se pueda prescindir de la concreción positiva que éstos reciben a lo largo de las disposiciones constitucionales. En este sentido, aunque implícitamente, ver también G. Peces-Barba, Los valores superiores, Tecnos, Madrid, 1984, pp. 70s, 97ss, 106. En efecto, si no fuese así, el recurso al Art. 1 dejaría libertad al intérprete para hacer prevaler, según su criterio, un valor por encima de otro, lo que sería peligroso especialmente en lo que se refiere a los valores que tienden a aparecer en conflicto: libertad e igualdad. En este sentido ver también L. López Guerra, en L. López Guerra et al., Derecho constitucional 2, Op. cit., pp. 33s.

${ }^{41}$ Igual reclamo a los valores del constitucionalismo clásico es hecho por G. Ferrara, La sovranità statale tra esercizio congiunto e delega permanente, Op. cit., pp. 678 ss. 
la manera de abordar los gravísimos problemas señalados al inicio de esta conferencia. Ciertamente, un planteamiento así sería bastante reductivo.

Es verdad que el inusual y rápido aumento de la temperatura de la tierra, el crecimiento de la población mundial a un ritmo vertiginoso, las condiciones infrahumanas de miles de millones de desamparados que viven en extrema pobreza etc., etc., representan escenarios verdaderamente preocupantes para el futuro de nuestros hijos y nietos; pero también lo es la obvia y sincera constatación de que el constitucionalismo, como doctrina, puede hacer poco para reducir la temperatura de la tierra o el hambre en el mundo; y no es menos cierto que, aquellos enunciados no son, por otra parte, los únicos problemas graves que en la práctica afectan a la humanidad. Bastaría hablar de los problemas jurídicos institucionales a los cuales deliberadamente no he hecho referencia: por ejemplo, la reforma de la onU, el proceso constituyente europeo actualmente en marcha, las cada vez mayores diferencias que se ponen de relieve entre el ámbito económico y el político y jurídico... ${ }^{42}$

En cambio, si se defiende que el verdadero reto del constitucionalismo es el que acabo de señalar, entonces la reafirmación del constitucionalismo como teoría jurídica de los límites al poder político se traduce, por sí, en un imperativo moral que, a modo de brújula, no sólo nos debería permitir tomar posición sobre los problemas "jurídicamente más abordables" por parte del constitucionalista, ya sean teóricos o prácticos (tales como, por ejemplo, el recurso a la tortura y la concentración del poder mediático), sino que además nos podría guiar también en la búsqueda de soluciones a problemas que quedan más alejados del objeto de nuestra disciplina, como son el aumento de la temperatura de la tierra, o la superpoblación, en el caso de que el análisis crítico de tales fenómenos nos lleve a la conclusión de que la causa sea imputable en alguna medida a decisiones o comportamientos de autorizados líderes políticos, religiosos o del mundo económico-empresarial: opiniones o comportamientos que, por tanto, pueden ser denunciados y combatidos.

Una segunda conclusión. La contribución de la civilización occidental al constitucionalismo ha sido determinante, y de eso no podemos dejar de sentirnos orgullosos. Más cuando, según se recuerda en el incipit de la Constitución europea, en la versión aprobada por la Convención, se hacen figurar -entre los valores que han servido de base al "humanismo"

${ }^{42}$ Sobre este último problema ver A. Baldassarre, Globalizzazione e internazionalizzazione delle decisioni, Op. cit., p. 81. 
desarrollado en Europa - el respeto a la razón, a la igualdad de los seres humanos y a la libertad.

El respeto a la razón ha constituido, efectivamente, el fundamento de la tolerancia frente a los discrepantes, la que -exaltada por Galileo, Spinoza, Milton y Locke (por citar sólo algunos de los grandes pensadores europeos) - ha representado, identificándose con la libertad de conciencia y de religión, el primero de nuestros modernos derechos civiles de libertad.

Esto nos permite dejar sentadas dos cosas. La primera es que los valores de nuestra civilización occidental -y de entre ellos, el constitucionalismo garantista, que arranca de una tradición milenaria- que se afirman (ideológicamente) como universales, no son tales, y por tanto, no pueden ser "impuestos" a los que pertenecen a otras culturas, pero sí pueden ser "propuestos", y que en la confrontación entre las ideas y los distintos valores existentes en el mundo puedan -nuestras ideas y nuestros valores- ser libremente aceptados "por otros", en la medida en que sean tenidos por "mejores".

Y eso vale también para la democracia tal y como nosotros los europeos la entendemos, que no se identifica con "el poder en las manos de la mayoría" (como se presenta en aquella cita de Tucídides, II, 37, puesta, ciertamente, con poca elegancia al inicio del proyecto de Constitución europea), sino con el sistema de gobierno que asegura el respeto de las minorías y la posibilidad de control por parte de éstas. El reconocimiento de los derechos y de las libertades - no debemos jamás olvidarlo- ha tenido siempre su origen en la lucha de las minorías oprimidas.

La segunda cosa que deriva de la premisa señalada más arriba, es la siguiente: que el reconocimiento de derechos para unos implica siempre el establecimiento de obligaciones para otros. ${ }^{43} \mathrm{Y}$ es, precisamente, sobre la base de la interdependencia de los derechos de los unos con las obligaciones correspondientes de los otros -y sobre la base de que nuestras constituciones no presuponen ya aquella separación Estado-sociedad característica de la teoría estatalista de los derechos públicos subjetivos-... es, ciertamente, sobre esas bases, donde el constitucionalismo moderno se preocupa por limitar el poder político, y también el privado, que tiene título para ocuparse, entre otros, de los problemas de la contaminación ambiental, del recalentamiento de la tierra, o de la "videopolítica". ${ }^{4}$

${ }^{43}$ Permitaseme la remisión a A. Pace, Problematica delle libertà costituzionali, Op. cit., pp. 20 ss.

${ }^{44}$ G. Sartori, "Videopolitica", Rivista italiana di scienza politica, 1989, pp. 185ss; 1d., Homo videns: televisione e postpensiero, Laterza, Bari-Roma, 1997. 
Tercera y última idea. No sé si en España los partidos políticos y los sindicatos atraviesan la misma crisis que ha golpeado a los partidos y a los sindicatos italianos -los primeros, a causa del rechazo, por parte de la opinión pública, de la "mediatización" desarrollada hasta 1993 (año de la abrogación - por medio de un referendum popular- del sistema de voto preferencial que tanto poder había llegado a atribuir a los partidos con el sistema electoral proporcional); los segundos, como consecuencia de la mutación que las nuevas profesiones y la mayor formación de los jóvenes han supuesto en el mundo laboral..$^{45}$ También me parece que puede afirmarse que tanto en España como en Italia está en crisis la "forma” del Estado-nación ${ }^{46}$ en razón de la fuerza en contrario que ejercen, de una parte, las respectivas comunidades territoriales, y de otra, la Unión Europea.

Que esto efectivamente supone un reto para el constitucionalismo europeo, aunque también - pero no sólo- para la solución de los problemas prácticos indicados al comienzo, me parece indiscutible. Se trata, en efecto, de forjar instrumentos mediante los cuales los particulares puedan influir ya sea en el llamado multilevel system of government que conecta a la Unión Europea y a los estados miembros, ya sobre los estados, a los cuales les queda "reservado el poder ejecutivo, es decir, aquel que está más directa e inmediatamente conectado con las concretas situaciones humanas" ${ }^{47}$ Se trata entonces no sólo de "construir la Unión Europea", sino también de "repensar el Estado" ${ }^{48}$ en relación con las funciones esenciales que ambos -UE y estados miembros- estarán llamados a ejercer en cuanto que "instrumentos" para el ejercicio de la soberanía del pueblo europeo ${ }^{49}$ (... siempre que a la frase de Tucídides, II, 37, se le quiera dar un sentido concreto).

Ciertamente, el situar fuera del Estado los poderes de decisión y el con-

\footnotetext{
${ }^{45}$ Sobre estos problemas ver, con su habitual agudeza, G. Amato, Tornare al futuro, Op. cit., p. 34ss. Ver Crisafulli, La sovranità popolare nella Costituzione italiana (Note preliminari) (1954), también en ld., Stato, popolo, governo. Illusioni e delusioni costituzionali, Giuffrè, Milano, 1985, pp. 103, 108. ${ }^{46}$ Precisamente A. Baldassarre, Globalizzazione e internazionalizzazione delle decisioni, Op. cit., $\mathrm{p}$. 85, observa que la crisis del Estado-nación no debe generalizarse, pues, por otra parte, en los estadosnación más fuertes, y especialmente en el más fuerte -Estados Unidos-, puede observarse una muestra de correspondencia entre nacionalismo e imperialismo.

${ }^{47}$ También G. Ferrara, "1 diritti politici nell'ordinamento europeo”, en Rassegna parlamentare, 1999, p. 808 ; 1d., La sovranità statale tra esercizio congiunto e delega permanente, Op. cit., p. 692.

${ }^{48}$ Ver las muchas e interesantes contribuciones publicadas en el volumen AA.W., Ripensare lo Stato, Op. cit., que recoge las actas del congreso celebrado en Nápoles los días 22 y 23 de marzo de 2002.

${ }^{49}$ En el sentido de que el Estado y los entes territoriales representan el instrumento para la afirmación de la soberanía popular ver V. Crisafulli, La sovranità popolare nella Costituzione italiana (Note preliminari) (1954), también en ld., Stato, popolo, governo. Illusioni e delusioni costituzionali, Giuffrè, Milano, 1985, p. 136.
} 
siguiente condicionamiento tanto de las decisiones presupuestarias como de gran parte de la legislación estatal, representa, para nosotros los europeos, un cambio histórico. Y lo es. Histórico fue también el giro que tuvo lugar a principios del xx, cuando el monolítico Estado liberal-autoritario entró en crisis como consecuencia de la reemergencia de los cuerpos intermedios que la revolución francesa había borrado (bajo la renovada forma de los sindicatos de trabajadores y de los partidos políticos de masas). ${ }^{50}$ Por eso hoy, como entonces, los constitucionalistas europeos están llamados a reflexionar sobre la efectividad de sus sistemas de representación política y sobre cómo puede ser eficazmente organizada la voluntad popular para influir en las decisiones de los gobernantes en Europa, cosa que será más urgente si, como parece, se acaba aprobando una Constitución europea sin que haya todavía un demos europeo... ${ }^{51}$

Y nosotros, los constitucionalistas, estamos llamados, al mismo tiempo, a reflexionar sobre cómo puede garantizarse la libertad (real y consabida) de los ciudadanos para elegir sus propios representantes, ya sea al Parlamento Europeo y a los parlamentos nacionales, en una época dominada por la "videopolítica". A propósito de esto último permítanme terminar con una pequeña glosa.

A través de las reseñas periodísticas que han aparecido he leído que en el recientísimo Reagan, a Life in Letters aparece reproducida una carta que el presidente Reagan - probablemente al final de su primer mandato- escribió a Charley Schultz, creador de los Peanuts, para rogarle que no propusiera a Snoopy a la presidencia de los Estados Unidos; y sin embargo, Reagan se empeñaba en nombrar a Snoopy secretario de Estado. Reagan obviamente bromeaba, pero - pienso yo- tampoco demasiado.

${ }^{50}$ Ver en particular las reflexiones de S. Romano, "Lo Stato moderno e la sua crisi" (1909), en 1d., Scritti minori, Vol. 1, Giuffrè, Milano, 1950, pp. 311ss. La obra de Romano, en la que se ilustra la pluralidad de los ordenamientos jurídicos y en donde por consiguiente desmonta en su fundamento la tesis, entonces dominante, del derecho como orden monolítico es, como es sabido, L'ordinamento giuridico, cuya primera edición aparece en los fascículos de 1917 y de 1918 de la revista Annali delle Università toscane. La segunda edición, realizada por Sansoni (Florencia), aparece, en 1945, sin cambios en el texto, pero con alguna adición en las notas. El parecido de la actual situación con aquella a la que se refería Santi Romano en Lo Stato moderno e la sua crisi me ha sido sugerido por G. Rebuffa, Dal costituzionalismo degli Stati al costituzionalismi dei diritti, en AA.W., Ripensare lo Stato, Op. cit., p. 65.

${ }^{51}$... con una notable inversión lógico-temporal que pone de manifiesto la finalidad ante todo "legitimante" que subyace en la elaboración del tratado por el que se instituye la Costitución europea. Sobre este punto, permítaseme la remisión a A. Pace, "La dichiarazione di Laeken e il processo costituente europeo”, Rivista trimestrale di diritto pubblico, 2002, pp. 613ss. 